\title{
Complete Atrioventricular Septal Defect with Tetralogy of Fallot
}

National Cancer Institute

\section{Source}

National Cancer Institute. Complete Atrioventricular Septal Defect with Tetralogy of

Fallot. NCI Thesaurus. Code C101322.

A rare congenital heart anomaly in which there is coexistence of tetralogy of Fallot and complete atrioventricular septal defect. The latter is characterized by defects in the atrial and ventricular septa and a common atrioventricular valve. 